Murray DS, Hager H, Tocher DR \& Kainz MJ (2015)

Docosahexaenoic acid in Arctic charr (Salvelinus alpinus): The importance of dietary supply and physiological response during the entire growth period, Comparative Biochemistry and Physiology - Part B: Biochemistry and Molecular Biology, 181, pp. 7-14.

This is the peer reviewed version of this article

NOTICE: this is the author's version of a work that was accepted for publication in Comparative Biochemistry and Physiology - Part B: Biochemistry and Molecular Biology. Changes resulting from the publishing process, such as peer review, editing, corrections, structural formatting, and other quality control mechanisms may not be reflected in this document. Changes may have been made to this work since it was submitted for publication. A definitive version was subsequently published in Comparative Biochemistry and Physiology Part B: Biochemistry and Molecular Biology, [VOL 181 (2015)] DOI:

http://dx.doi.org/10.1016/j.cbpb.2014.11.003 


\section{Docosahexaenoic acid in Arctic charr (Salvelinus alpinus) - the importance of dietary supply and physiological response during the entire growth period}

David S. Murray ${ }^{\mathrm{a}}$, Hannes Hager ${ }^{\mathrm{a}}$, Douglas R. Tocher ${ }^{\mathrm{b}}$, Martin J. Kainz
${ }^{\mathrm{a}}$ WasserCluster - Biologische Station Lunz, 3293 Lunz am See, Austria.

${ }^{b}$ Institute of Aquaculture, School of Natural Sciences, University of Stirling, Stirling, FK9 4LA, Scotland, UK.

Email: david.murray@wcl.ac.at; hannes.hager@wcl.ac.at; d.r.tocher@stir.ac.uk; martin.kainz@donau-uni.ac.at

Corresponding author: David S. Murray

Office phone number: $(+43) 7486-20060$

Mobile number: $(+43)$ 6802-202422

Fax number: (+43) 7486-2006020 
The aim of this 14-month feeding study was to investigate the effects of dietary docosahexaenoic acid (DHA) on tissue fatty acid composition, DHA retention and DHA content per biomass accrual in muscle tissues of Arctic charr (Salvelinus alpinus). A control feed, formulated with a relatively high DHA inclusion level $(\mathrm{F} 1)$, was compared with feeds containing gradually reduced amounts of DHA (Feeds F2, F3, and F4). Arctic charr were randomly distributed among 12 tanks and fed one of the feeds in triplicate. The DHA content within muscle tissues of fish fed diets F1 and F2 was generally higher compared to fish fed diets F3 and F4. However, there was an interaction between dietary DHA treatment and season, which resulted in fish muscle tissues having similar DHA contents irrespective of dietary supply during specific sampling periods. Although diets F3 and F4 contained $\sim$-fold less DHA compared to diets F1 and F2, retention of DHA in dorsal and ventral muscle tissue was up to 5-fold higher relative to the diet content in fish fed diets F3 and F4. However, the difference among treatments was dependent on the month sampled. In addition, younger fish retained DHA more efficiently compared to older fish. DHA ( $\mu \mathrm{g} \mathrm{DHA} / \mathrm{g} / \mathrm{day})$ accrual in muscle tissue was independent of somatic growth, and there was no difference among treatments. The results suggested that dietary DHA may be essential throughout the lifecycle of Arctic charr and that the DHA content of muscle tissues was influenced by diet and metabolic/physiological factors, such as specific DHA retention during the entire growth cycle. Finally, this long-term feeding study in Arctic charr indicated a non-linear function in DHA retention in dorsal and ventral muscle tissues throughout the lifecycle, which varied in its relationship to dietary $\mathrm{DHA}$.

Keywords: Retention; PUFA; Nutrition; Fish; Fatty acid; DHA; Aquaculture 


\section{Introduction}

Likely all fish require dietary omega-3 long-chain polyunsaturated fatty acids ( $\mathrm{n}$ 3 LC-PUFA) as nutrients that function as structural components for cell membranes and facilitate somatic growth and development (Glencross 2009; Glencross et al., 2014). However, the fatty acid (FA) composition of fish tissues appears to vary widely among species (Glencross 2009). Studies regarding the importance of specific FA in farmed and wild fish populations suggested that FA compositions of fish tissue lipids usually reflected those of dietary lipids, meaning that tissue FA profiles can be modified by altering the types of dietary fats and oils consumed by fish (Bell et al., 2001; Jobling et al., 2003, 2004; Sargent et al., 1995). This forms the basis for the use of FA as dietary biomarkers in food web studies (Kirsch et al., 1998) and assumes that the fish do not considerably alter dietary FA.

While it is often assumed that tissue FA reflects dietary FA compositions, recent studies showed that fish metabolism and physiology are also important in influencing the final tissue FA composition in farmed and wild fish. For instance, during FA metabolism many fish, including salmonids such as Atlantic salmon (Salmo salar), brown trout (Salmo trutta) and Arctic charr (Salvelinus alpinus), can convert, albeit rather inefficiently, $\alpha$-linolenic acid (LNA; 18:3n-3) to the $n$ 3 LC-PUFA eicosapentaenoic acid (EPA; 20:5n-3) and docosahexaenoic acid (DHA; 22:6n-3) (Tocher 2003; Murray et al., 2014). Furthermore, when analysing FA retention efficiencies, there are distinct differences in the utilisation of different FA (Glencross et al., 2014). For example, previous studies have shown that DHA is preferentially retained in fish tissues when dietary sources are limited (Glencross et al., 2003; 2014 Glencross and Rutherford, 2011; Murray et al., 2014).

The fact that fish can preferentially retain and/or endogenously synthesise DHA may highlight how important this particular LC-PUFA is for somatic development as all FA can also be B-oxidised to produce metabolic energy (Bell et al., 2002; Tocher 2003). Previous studies have shown that fish fed DHA deficient diets have significantly lower growth rates compared to fish fed diets relatively rich in DHA (Murray et al., 2014). 
The majority of studies examining tissue FA compositions focused on the influences of dietary FA on muscle tissue composition and somatic growth (Glencross et al., 2014; Czesny et al., 1999). Furthermore, many studies were performed over relatively short periods of time, typically between 8-16 weeks (Turchini et al., 2009), and on different stages of development (Glencross et al., 2003, 2014; Sheridan et al., 1985). Although salmonids are a successfully farmed fish family, DHA requirements are not well defined and information regarding DHA composition in tissues over an entire lifecycle is essential in understanding those requirements. However, few studies have thus far investigated how fish accumulate and retain DHA in tissues over an entire lifecycle in an effort to elucidate the presumably continuous somatic requirement of this n-3 LC-PUFA.

In the current study we examined the effect of four dietary treatments containing decreasing dietary DHA on tissue FA compositions, DHA retention ratios, and DHA content per biomass accrual in Arctic charr muscle tissue over an entire production cycle of 14 months. We tested the hypothesis that the mass ratios of DHA (i.e., mg DHA per g muscle tissue) accrued would not differ among fish fed diets containing high and low mass ratios of DHA throughout the lifecycle. Our underlying assumption was that fish fed on DHA deficient diets would specifically retain and accrue DHA in muscle tissue and that DHA retention was independent of somatic growth.

\section{Materials and methods}

\subsection{Fish, husbandry and experimental diets}

Third generation farmed Arctic charr (15-20 g body weight) of the same strain (hatchery-reared in Lunz am See, Austria) were held in aquarium facilities at the WasserCluster Research Centre from August 2012 until October 2013. The experiment was conducted in a flow-through system containing 12 rectangular tanks (1000 L each) with a continuous supply of gravel-filtered spring water (ca. $25 \mathrm{~L} \mathrm{~min}^{-1}$ ). Waste water was drained using a sink hole covered by a $5 \mathrm{~mm}$ mesh 
screen. Fish were subjected to natural photoperiod (latitude $=47.8604{ }^{\circ} \mathrm{N}$ ), delivered by artificial fluorescent lighting and adjusted weekly. A total of 1200 juvenile Arctic charr were randomly distributed as 100 fish of mixed sexes per tank. Dissolved oxygen, $\mathrm{pH}$, and water temperature were recorded daily. Throughout the long-term feeding trial, Arctic charr was exposed to natural (ambient) water temperature $\left(3.7^{\circ} \mathrm{C}\right.$ to $12.3^{\circ} \mathrm{C}$; mean $=7.9^{\circ} \mathrm{C}$ ), dissolved oxygen (7.3 to $11.4 \mathrm{mg} \mathrm{L}^{-1}$; mean $\left.=9.2 \mathrm{mg} \mathrm{L}^{-1}\right)$ and approximately neutral $\mathrm{pH}$ values $(6.7$ to 7.7 ; mean $=7.4)$.

Four isocaloric fish feeds were formulated (Garant ${ }^{T M}$, Austria) to provide sufficient lipid and protein to meet somatic requirements of salmonids (NRC, 2011) (Table 1). Fish in triplicate tanks were fed one of the four different diets that contained gradually less DHA (Table 2). Diets were dispensed daily into the tank by a clockwork belt feeder (Dryden Aqua Ltd., Edinburgh, UK) over a $12 \mathrm{~h}$ feeding period. The daily feed ration exceeded the recommended feeding rate for salmonids for the prevailing water temperature. Uneaten feed was collected to accurately determine feed intake per tank.

\subsection{Proximate analysis}

The gross nutrient composition of the four experimental diets was determined as described below (Table 3 ). Moisture was determined by drying to constant weight in an oven at $110^{\circ} \mathrm{C}$ for $24 \mathrm{~h}$ (Bell et al., 2003). Sample weight was recorded before drying and after removal from the oven. This process was repeated at $1 \mathrm{~h}$ intervals until weight change was $<5 \mathrm{mg}$. Total protein content in experimental diets was determined by a modified Bradford assay (Murray et al., 2013) and total lipids by solvent extraction and gravimetric determination (Heissenberger et al., 2010). Ash content was determined by placing preweighed diets in a muffle furnace at $550^{\circ} \mathrm{C}$ for $8 \mathrm{~h}$ or until white ash was obtained (Bell et al., 2003) that was subsequently weighed.

\subsection{Sampling procedure}


Twelve fish were selected at random, 3 replicates per treatment, and weighed during November, February, April, June, August, October. Fish were killed by a blow to the head and samples of muscle dissected and stored in plastic vials (8 $\mathrm{mL})$. Muscle samples were obtained by cutting a fillet from the fish and separating the two sections using the lateral line as a border between the dorsal and ventral tissue. Care was taken to prevent any skin or bone from being included in the sample. All tissue samples were stored at $-80^{\circ} \mathrm{C}$ overnight and freeze dried before analysis.

\subsection{Lipid extraction and fatty acid analysis}

Total lipids from homogenised, freeze-dried dorsal and ventral muscle samples (25-35 mg) were analysed as in Heissenberger et al. (2010). In brief, samples were sonicated and vortexed in chloroform/methanol (2:1 by volume). Organic layers were removed and transferred into solvent-rinsed vials. For gravimetric determination of total lipid contents (i.e., mg lipids g dry weight ${ }^{-1}$ ), triplicate subsamples $(100 \mu \mathrm{L})$ of the extracts were evaporated and weighed. Fatty acids were derivatised to obtain fatty acid methyl esters (FAME) using toluene and sulphuric acid-methanol solution $\left(1 \% \mathrm{v} / \mathrm{v}, 16 \mathrm{~h}\right.$ at $\left.50^{\circ} \mathrm{C}\right)$. In contrast to Heissenberger et al. (2010), hexane without butylated hydroxytoluene (BHT) was used for each washing step after methylation to avoid BHT-related peak interference in chromatograms. FAME were identified by comparison with known standards (Supelco37 FAME Mix) using a gas chromatograph (Thermo Scientific TRACE GC Ultra ${ }^{\mathrm{TM}}$ ) equipped with a flame ionisation detector (FID) and a Supelco ${ }^{\text {TM }}$ SP-2560 column (100 m, 25 mm i.d., $0.2 \mu \mathrm{m}$ film thickness). Quantification of FA was performed by comparison with a known concentration of the internal standard using Excalibur 1.4 $4^{\mathrm{TM}}$ (Thermo Electron Corporation).

\subsection{Data analysis}

Significant differences among dietary treatments were determined by one-way ANOVA and interactions between treatment and season were determined using general linear models (GLM). Differences between means were 
determined by Tukey's HSD test. Relationships between retention ratios and somatic growth was analysed using linear regressions. Data identified as nonhomogeneous, using variance test, were subjected to log transformation before applying the statistical tests. The Minitab ${ }^{\circledR} 16$ statistical software package was used for data analysis and the significance level was set at $p=0.05$. Feed conversion ratios (FCR) where determined as the quotient of feed consumed and increase in fish biomass, feed intake (g)/weight gain (g). Fatty acid retention ratios were determined as the quotient of FA in fish muscle tissues and FA in the respective diet (mg FA per g of dry weight/diet); i.e., $[\mathrm{DHA}]_{\text {fish }} /[\mathrm{DHA}]_{\text {diet }}$. We define retention as the ability of fish to regulate and control ingested FA in their tissues (Kainz et al., 2004). Fatty acid biomass accrual was determined as the quotient of measured FA over time (mg FA per $\mathrm{g}$ of dry weight/time) i.e., $[D H A]_{\text {fish }} /$ time(days). Furthermore, we define DHA biomass accrual as the DHA content in muscle tissue per weight of fish, which was normalised to account for differences in somatic growth (i.e. DHA per unit biomass accrual).

\section{Results}

\subsection{Diet composition, fish growth and feed utilisation}

Dietary lipid content was similar among treatments. There was a 1.6-fold decrease in total n-3 PUFA contents between diets F1 and F4, specifically a 4.0 and 4.2-fold decrease in the proportions DHA and EPA, respectively (Table 2). Alternatively, total n-6 PUFA contents increased 1.4-fold and LNA by 1.6-fold between diets F1-F4 (Table 2).

Dietary treatment had a significant effect on final weight $\left(\mathrm{F}_{[3-11]}=26.70\right.$; $\left.R^{2}=0.875 ; P<0.001\right)$ (Table 4). Fish fed dietary treatment F1 (350.0 \pm 22.8 $\mathrm{g} /$ fish) and F2 (291.9 $\pm 1.4 \mathrm{~g} /$ fish) had significantly higher final weights compared to fish fed F4 $(236.3 \pm 16.9 \mathrm{~g} /$ fish $)$ diets. Weight gain of fish among treatments was also significantly different $\left(F_{[3-11]}=26.41 ; R^{2}=0.874 ; P<0.001\right)$ (Table 4). Fish fed dietary treatments F1 and F2 gained significantly more weight 
(338.8 $\pm 22.5 \mathrm{~g}$ / fish and $281.6 \pm 12.2 \mathrm{~g}$ / fish, respectively) compared to fish fed diet F4 $(226.0 \pm 17.1 \mathrm{~g} /$ fish $)$. Significant differences in FCR were also observed during the experiment $\left(\left(\mathrm{F}_{[3-92]}=26.41 ; \mathrm{R}^{2}=0.501 ; \mathrm{P}<0.001\right)\right.$. Fish fed diet $\mathrm{F} 1$ $(0.91 \pm 0.04)$ had significantly lower FCR compared to fish fed diet F2 $(1.02 \pm$ 0.05, F3 $(1.06 \pm 0.09)$ and F4 $(1.13 \pm 0.11)$ (Table 4). Regression analysis showed no linear relationship between fish weight and dietary or tissue DHA contents.

3.2 Effect of seasonality on tissue DHA content in fish fed different diets.

There were no significant differences in DHA contents of dorsal or ventral muscle among fish fed the different dietary treatments at the end of the feeding experiment (Fig. 1). Seasonality interacted significantly with diet treatments for DHA in dorsal muscle $\left(F_{[15-71]}=2.12 ; R^{2}=0.728 ; P=0.025\right)$ (Fig. 1). In February, fish fed diet F1 had significantly higher DHA $(61.2 \pm 11.0 \mathrm{mg}$ DHA/g total lipids; $\left.F_{[3-11]}=6.52 ; R^{2}=0.710 ; P=0.015\right)$ compared to fish fed dietary treatment $F 4$ (25.2 $\pm 10.2 \mathrm{mg} \mathrm{DHA} / \mathrm{g}$ total lipids). In April, dorsal muscle DHA in fish fed diets F1 (126.1 $\pm 30.3 \mathrm{mg} \mathrm{DHA} / \mathrm{g}$ total lipids) and F2 $(148.7 \pm 13.8 \mathrm{mg}$ DHA/g total lipids) were significantly higher $\left(F_{[3-11]}=9.34 ; R^{2}=0.778 ; P=0.005\right)$ compared to fish fed diet F4 (56.0 $\pm 17.2 \mathrm{mg} \mathrm{DHA} / \mathrm{g}$ total lipids). In August, fish fed diets F1 (137.8 $\pm 6.3 \mathrm{mg}$ DHA/g total lipids) and F2 $(125.4 \pm 32.3 \mathrm{mg} \mathrm{DHA} / \mathrm{g}$ total lipids) also had significantly higher DHA in dorsal muscle $\left(F_{[3-11]}=33.09 ; R^{2}=0.925 ; P<\right.$ $0.001)$ compared to fish fed diets F3 $(22.8 \pm 17.7 \mathrm{mg}$ DHA/g total lipids) and F4 (20.8 $\pm 8.4 \mathrm{mg} \mathrm{DHA} / \mathrm{g}$ total lipids). There were, however, no significant effects of dietary treatment on DHA contents of dorsal muscle in fish sampled during November, June or October (Fig. 1).

Similarly, seasonality showed a significant interaction with dietary treatment in ventral muscle DHA $\left(F_{[15-71]}=2.03 ; R^{2}=0.749 ; P=0.033\right)$ (Fig. 2). In April, ventral muscle DHA contents were significantly higher in fish fed diets F1, $\mathrm{F} 2$, and F3 $(118.6 \pm 14.1,120.4 \pm 39.5$, and $95.7 \pm 19.0 \mathrm{mg} \mathrm{DHA} / \mathrm{g}$ total lipid, respectively; $F_{[3-11]}=10.79 ; R^{2}=0.802 ; P=0.003$ ) compared to fish fed diet $F 4$ (38.5 $\pm 15.8 \mathrm{mg} \mathrm{DHA} / \mathrm{g}$ total lipids). There were no significant differences in DHA ventral muscle contents among fish sampled during November, February, June, August or October (Fig. 2). 
Dorsal and ventral muscle DHA contents in fish fed diets F3 and F4 were generally, but not significantly lower compared to fish fed diets F1 and F2. The seasonal patterns of DHA content in dorsal muscle were similar between November and June independent of dietary treatment (Fig. 1); fish fed diets F1, $\mathrm{F} 2$ and $\mathrm{F} 3$ diets showed a 3 -fold increase in DHA in dorsal muscle, while DHA content doubled in fish fed diet F4. Between June and October, the pattern of DHA between fish fed high (F1 and F2) and low (F3 and F4) DHA diets diverged; by August, the DHA content in fish fed diets F1 and was 6 to 7 -fold higher than in fish fed diets $\mathrm{F} 3$ and F4, while it converged again by October at the end of the trial. In general, DHA in ventral muscle tissue followed a similar pattern independent of dietary treatment (Fig 2). Between February and April there was a large increase in DHA with fish fed diets F1 and F2 diets showing levels increased 4- and 2-fold, respectively, and fish fed diets F3 and F4 showing increases of 2- and 1.5-fold, respectively (Fig. 2). From April to October, DHA levels increased 3 -fold in fish fed diets F1 and F2, and 2-fold in fish fed diets F3 and F4 (Fig. 2).

\subsection{DHA in muscle tissues per biomass accrual}

There was no significant difference in DHA contents in dorsal (Fig. 3) or ventral (Fig. 4) muscle tissues per biomass accrual among the different dietary treatments. Both tissues follow similar patterns independent of dietary DHA supply with highest $\mathrm{DHA}$ accrual ( $\mu \mathrm{g} \mathrm{DHA} / \mathrm{g} /$ day) at the beginning of the trial in juvenile Arctic charr (November) with a sharp decrease ( $\sim$-fold in dorsal and ventral muscle tissues) until February, followed by consistent increase until April, but with generally lower DHA content in both ventral and dorsal muscle tissues per biomass accrual until the end of the trial. 
Retention ratios of DHA in dorsal $\left(F[3-11]=28.10 ; R^{2}=0.913 ; P<0.001\right)$ and ventral $\left(F[3-11]=38.98 ; R^{2}=0.936 ; P<0.001\right)$ muscle tissue differed significantly at the end of the feeding experiment (October). In dorsal muscle, fish fed diets F3 $(3.3 \pm 0.8)$ and F4 $(3.3 \pm 0.2)$ had significantly higher retention ratios compared to fish fed diets F1 $(1.1 \pm 0.3)$ and F2 (1.3 \pm 0.2$)$ (Fig. 5$)$. In ventral muscle tissues, fish fed diets F3 $(4.5 \pm 0.9)$ and F4 $(3.3 \pm 0.4)$ also had significantly higher retention ratios compared to fish fed diets F1 $(1.0 \pm 0.1)$ and F2 $(1.3 \pm 0.4)$ (Fig. 6). There was no significant interaction between season and dietary treatment in DHA retention ratios of dorsal or ventral muscle tissues. However, differences in DHA retention ratios between dietary treatments all varied on a monthly basis (Fig. 5 and 6 ).

In dorsal muscle from fish sampled during November, DHA retention in fish fed diet F4 $(4.6 \pm 1.5)$ was significantly higher $\left(F[3-11]=5.14 ; R^{2}=0.530 ; P=\right.$ 0.029) compared to fish fed diet F1 (3.8 \pm 0.7$)$ (Fig. 5). Retention of DHA in April was also significantly higher $\left(F[3-11]=12.65 ; R^{2}=0.826 ; P=0.002\right)$ in fish fed diets F3 $(4.3 \pm 0.6)$ and F4 $(5.5 \pm 3.0)$ compared to fish fed diets F1 $(1.2 \pm 0.1)$ and F2 $(1.5 \pm 0.1)$ (Fig. 5). There were no significant differences in DHA retention ratios in dorsal muscle tissue during February, June or August (Fig. 5).

Retention of DHA in ventral muscle of fish fed diets F3 $(3.6 \pm 0.4)$ and F4 $(4.6 \pm 1.5)$ was significantly higher $\left(F[3-11]=8.23 ; R^{2}=0.755 ; P=0.008\right)$ than in fish fed diet F1 (1.3 \pm 0.3 ) during November (Fig. 6). In February, fish fed diets F3 $(2.3 \pm 0.1)$ and $F 4(2.5 \pm 0.4)$ also retained significantly higher $\left(F[3-11]=6.12 ; R^{2}=\right.$ 0.697; $P=0.018)$ levels of DHA in ventral muscle than fish fed diet F1 $(0.6 \pm 0.5)$

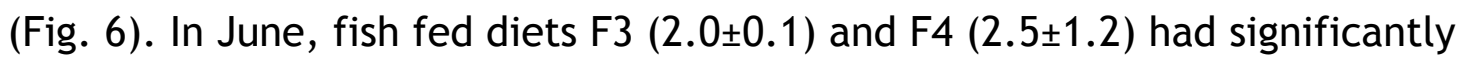
higher $\left(F[3-11]=8.93 ; R^{2}=0.770 ; P=0.006\right) D H A$ retention ratios compared to fish fed diets F1 $(0.9 \pm 0.4)$ and F2 (0.8 \pm 0.0$)$ (Fig. 6). Ventral muscle DHA retention ratios in fish fed diets F3 $(1.9 \pm 1.0)$ and F4 $(2.6 \pm 0.5)$ were significantly higher $\left(F[3-11]=7.39 ; R^{2}=0.735 ; P=0.011\right)$ than fish fed diet $F 2(0.4 \pm 0.2)$ in August (Fig. 6). 
3.5 Relationships between DHA retention ratios in muscle tissue and weight of Arctic charr

DHA retention in dorsal $\left(R^{2}=0.22 ; P<0.001\right)$ and ventral $\left(R^{2}=0.16 ; P=\right.$ 0.001 ) muscle tissues decreased significantly from juvenile to adult fish (Figs. 7 and 8 , respectively). The linear relationship between DHA retention in muscle tissue and fish weight depended on dietary treatments. In dorsal muscle, there was a significant negative relationship between fish weight and $D H A$ retention ratios for fish fed diets $F 1\left(R^{2}=0.31, P=0.017\right), F 3\left(R^{2}=0.30, P=0.019\right)$ and $F 4$ $\left(R^{2}=0.22, P=0.048\right)$, but not fish fed diet F2 (Fig. 7). In ventral muscle, there was also a significant negative relationship between fish weight and DHA retention ratio for fish fed diets $F 2\left(R^{2}=0.28, P=0.022\right)$ and $F 3\left(R^{2}=0.27, P=\right.$ 0.027), but not fish fed diets F1 and F4 (Fig 8).

\section{Discussion}

This study demonstrated that both dietary DHA supply and fish physiology during the entire growth cycle affect DHA retention efficiency and, consequently, DHA contents in dorsal and ventral muscle tissues of Arctic charr. One possible explanation underpinning DHA retention in fish and the higher DHA content compared to all other FA is that DHA is not easily $\beta$-oxidised as the $\Delta 4$ double bond requires peroxisomal oxidation (Sargent et al., 2002; Tocher, 2003). However, this biochemical mechanism based on enzyme specificities and activities may not be the only one involved and the present study has suggested that other processes may also interact to affect DHA retention. Final weights and weight gain in fish fed low amounts of dietary DHA (F3-F4) were lower compared to fish supplied with higher amounts of DHA (F1-F2). Furthermore, FCR was also highest in fish supplied with the lowest amount of DHA (F4). In addition, fish fed lower dietary DHA had correspondingly generally lower DHA contents in muscle tissues, but higher DHA retention ratios compared to fish supplied with higher dietary DHA. The similar DHA content per unit biomass accrual was largely independent of dietary DHA supply, indicating that increased 
DHA retention in Arctic charr compensates, at least partly, for dietary deficits. However, this effect appeared more pronounced in younger fish as evidenced by the decreased DHA retention ratios in muscle tissues in fish of increasing size and thus age. Furthermore, the present study also showed that, independent of dietary DHA supply, DHA in muscle tissues fluctuated during the lifecycle of Arctic charr, which suggests that DHA metabolism in Arctic charr may change with extrinsic factors, such as water temperature (Farkas et al., 1980), as well as intrinsic factors, such as gonadal development (Hiratsuka et al., 2004). This long-term study has thus provided better resolution of DHA retention in tissues over time compared to shorter feeding studies that can miss seasonal fluctuations.

The present study demonstrated that diets containing lower amounts of DHA resulted in lower final weights and reduced weight gain, particularly with the lowest inclusion levels (diet F4) compared to fish fed F1 and F2 diets. In addition, FCR was lower in fish fed the F1 diet compared to all other dietary treatments. These results are in contrast to previous studies which showed no significant impact of lower dietary DHA on growth rates and/or final fish weights (Gomes et al., 1995, Guillou et al., 1995; Kaushik et al., 1995; Pettersson et al., 2009) and no significant differences in FCR of farmed fish (Azevedo et al., 2004; Bendiksen et al., 2003; Karalazos et al., 2011). Many studies examining the effect of fatty acid content on final weights and weight gain were performed over relatively short time scales (Turchini et al., 2009). For example studies reporting no significant difference in growth rates between fish consuming high and low amounts of DHA were performed between 12 and 21 weeks (Bell et al., 2001, 2003; Tocher et al., 2000, 2001; Torstensen et al., 2000).

However, the current study showed no significant relationship between DHA and fish weight. A previous study found that, after 50 wks of feeding, Atlantic salmon fed low amounts of DHA (2.9 and $3.4 \mathrm{~g} / 100 \mathrm{~g}$ of total fatty acids) had significantly higher weights compared to fish fed higher amounts of DHA (10.5g/100g of total fatty acids) (Bell et al., 2003). Therefore the lower growth rates in fish fed diets F2- F4 in the current study may have been a consequence of the replacement of fish meal with pumpkin kernel cake. Pumpkins contain high contents of neutral and acid detergent fibre (Suara-Calixto et al. 1983) that affect digestive functions by increasing intestinal flow rates (Lienner 1980, 
Krogdahl 1989; Nyina-Wamwiza et al. 2010), which may reduce the retention of dietary nutrients (Krogdahl 1989). This suggested that a 2-fold increase in pumpkin kernel cake in the present study may have affected nutrient absorption, resulting in the lower growth rates of fish fed dietary treatments F2, F3 and F4.

Dietary DHA supply did not fully predict the DHA content in dorsal or ventral muscle tissues of Arctic charr. There were significant interactions between dietary treatment and season in both muscle tissues. In general, DHA content was higher in fish fed F1 and F2 diets, but these results depended on the month sampled. Previous studies have shown that dietary FA requirements for fish differ depending on life history stage (Izquierdo et al., 1996; 2001), thus we may expect that tissue FA compositions in fish vary similarly reflecting the different biological requirements associated with each stage of their lifecycle. Sheridan et al., (1985) found significant differences in FA in muscle tissues between different life history stages of steelhead trout (Oncorhynchus mykiss) fed the same diet. The DHA content of smolt muscle tissue was significantly higher compared to parr muscle tissue. This suggested that fish may require different amounts of DHA at different stages of development to support crucial, albeit not clearly defined, biological functions.

Despite a four-fold decrease in DHA mass ratios between F1/F2 and F3/F4 diets there were no significant differences in DHA per unit biomass accrual among treatments in both dorsal and ventral muscle tissues. It is known that DHA, with its long carbon chain length and high number of double bonds, provides cell membranes with high flexibility, which improves cellular functions (Arts and Kohler, 2009; Eldho et al., 2003; Weigand 1996). Indeed, Arctic charr provided with the lowest dietary DHA generally showed the highest retention ratios in both dorsal and ventral muscle tissues, indicating that in the absence of or reduced dietary DHA, Arctic charr may preferentially retain and/or synthesise DHA. Turchini and Francis (2003) stated that high deposition of DHA in tissues, in fish fed low dietary DHA, may be due to endogenous synthesis of DHA. Murray et al. (2014) found that there was a trend towards higher DHA synthesis in Artic charr fed diets containing low DHA. Such endogenous synthesis of DHA may be required to support cell and other physiological functions when dietary DHA supply is low. 
The DHA mass ratios retained generally mirrors the DHA content in Arctic charr muscle tissue. For example, the DHA content in muscle tissue of fish fed F3 and F4 diets was high (i.e. April), retention ratios of DHA were high. Previous studies also report that Atlantic salmon (Glencross et al., 2014) and European sea bass (Dicentrarchus labrax) (Mourente and Bell, 2006) have substantially higher DHA retention ratios in tissues when fed diets containing low or no DHA. These studies investigated this process over a much shorter time scale (9-20 weeks) compared to the current study (60 weeks), which found that the degree to which the retention ratios differed among treatments changed depending on the month sampled and thus on the specific stage of somatic fish development. For example, although DHA retention ratios in fish fed diets F3 and F4 were generally higher, there was no significant difference in dorsal muscle DHA retention ratios among treatments in February, June, and August. These results indicated that, although fish require high DHA throughout their lifecycle, their ability to retain DHA within muscle tissue fluctuated on a month-by-month basis.

Juvenile Arctic charr retained more DHA in dorsal and ventral muscle tissue compared to adult charr. However, this relationship was dependent on dietary treatment. The somatic requirement for DHA is higher in juvenile and sub-adult fish when a large portion of DHA, supporting rapid growth, is directed towards the formation of cell membranes vital for normal development and functioning of tissues (Izquiredo 1996; Mourente et al., 1991; Tocher et al., 1985). DHA in muscle mostly originates from dietary supplies and, in part, from endogenous synthesis from shorter chain precursors in liver (Tocher 2003). Therefore, the present results suggested that juvenile Arctic charr are more efficient at retaining dietary DHA and/or the amount of DHA synthesised de novo is higher compared to adult Arctic charr. Tocher et al. (2003) found that endogenous synthesis of DHA was higher in juvenile Atlantic salmon (parr) compared to older Atlantic salmon (smolt). During later stages of development, fish allocate energy to gonadal maturation (Izquiredo et al., 2001; Mourente and Odriozola, 1990; Wiegand 1996) and thus retention of DHA in somatic tissues may be reduced in sexually mature adults.

In conclusion the present study suggests that dietary inclusion of DHA affects both the content and retention of DHA in dorsal and ventral muscle tissues. However, over the course of an entire lifecycle the significance of these 
differences varied suggesting that other factors, such as age and stage of sexual development, may also influence the content and retention of DHA in somatic tissues. Although there was a trend towards lower DHA in muscle tissue of fish provided with 4-fold lower dietary DHA, these Arctic charr were able to retain as much as 5-fold more DHA in muscle tissues compared to fish fed the highest dietary DHA inclusion. Furthermore, despite differences in dietary DHA levels, DHA accrual was similar among dietary treatments independent of somatic growth, but varied over time. Therefore, the results suggested that dietary DHA was not the sole predictor of DHA in muscle tissues of Arctic charr and that the DHA content of diets could be assessed based on the ability of the species to specifically retain and/or endogenously synthesise DHA, the age of the fish, and the stage of sexual development.

\section{Acknowledgements}

This work received financial support by the Austrian Ministry of Life (project $\mathrm{Nr}$. 100837; BMLFUW-LE.1.3.2/0051-II/1/2012) and GARANT Tiernahrung Austria. We are grateful for technical assistance and support from Eduard Schneeberger, and veterinary supervision by Heinz Heistinger. We also thank Katharina Drucker, Katharina Hader, Katharina Winter, and Zahra Changizi for their laboratory assistance.

\section{References}

Arts, M.T., Kohler, C.C., 2009. Health and condition in fish: the influence of lipids on membrane competency and immune response, Lipids in aquatic ecosystems. Springer, pp. 237-256.

Azevedo P.A., Leeson S., Cho C.Y., Bureau, D.P. 2004. Growth, nitrogen and energy utilization of juveniles from four salmonid species: diet, species and size effects. Aquaculture 234, 393414.

Bell, J.G., Farndale, B.M., Bruce, M.P., Navas, J.M., Carillo, M., 1997. Effects of broodstock dietary lipid on fatty acid compositions of eggs from sea bass (Dicentrarchus labrax). Aquaculture 149, 107-119.

Bell, J.G., Henderson, R.J., Tocher, D.R., McGhee, F., Dick, J.R., Porter, A., Smullen, R.P., Sargent, J.R., 2002. Substituting fish oil with crude palm oil in the diet of Atlantic salmon (Salmo salar) affects muscle fatty acid composition and hepatic fatty acid metabolism. The Journal of Nutrition 132, 222-230.

Bell, J.G., McEvoy, J., Tocher, D.R., McGhee, F., Campbell, P.J., Sargent, J.R., 2001. 
Replacement of fish oil with rapeseed oil in diets of Atlantic salmon (Salmo salar) affects tissue lipid compositions and hepatocyte fatty acid metabolism. The Journal of Nutrition $131,1535-1543$.

Bell, J.G., Tocher, D.R., Henderson, R.J., Dick, J.R., Crampton, V.O., 2003. Altered Fatty Acid Compositions in Atlantic Salmon (Salmo salar) Fed Diets Containing Linseed and Rapeseed Oils Can Be Partially Restored by a Subsequent Fish Oil Finishing Diet. Journal of Nutrition, 133, 2793-2801.

Bendiksen EÅ, Berg OK, Jobling M., Arnesen, A.M., Måsøvalb, K., 2003. Digestibility, growth and nutrient utilisation of Atlantic salmon parr (Salmo salar L.) in relation to temperature, feed fat content and oil source. Aquaculture 224, 283-299.

Czesny, S., Kolkovski, S., Dabrowski, K., Culver, D., 1999. Growth, survival, and quality of juvenile walleye Stizostedion vitreum as influenced by $n-3$ HUFA enriched Artemia nauplii. Aquaculture 178, 103-115.

Eldho, N.V., Feller, S.E., Tristram-Nagle, S., Polozov, I.V., Gawrisch, K., 2003. Polyunsaturated docosahexaenoic vs docosapentaenoic acid differences in lipid matrix properties from the loss of one double bond. Journal of the American Chemical Society 125, 6409-6421.

Farkas, T., Csengeri, I., Majoros, F., Olah J., 1980. Metabolism of fatty acids in fish. III. Combined effect of environmental temperature and diet in formation and deposition of fatty acids in the carp, Cyprinus carpio Linnaeus 1758. Aquaculture 20, 29-40.

Glencross, B.D., 2009. Exploring the nutritional demand for essential fatty acids by aquaculture species. Reviews in Aquaculture 1, 71-124

Glencross, B.D., Hawkins, W.E., Curnow, J.G., 2003. Restoration of the fatty acid composition of red seabream (Pagrus auratus) using a fish oil finishing diet after grow-out on plant oil based diets. Aquaculture Nutrition 9, 409-418.

Glencross, B.D., Rutherford, N.R., 2011. The docosahexaenoic acid (DHA) requirements of juvenile barramundi (Lates calcarifer). Aquaculture Nutrition 17, 536-548

Glencross, B., Tocher, D., Matthew, C., Gordon Bell, J., 2014. Interactions between dietary docosahexaenoic acid and other long-chain polyunsaturated fatty acids on performance and fatty acid retention in post-smolt Atlantic salmon (Salmo salar). Fish Physiology and Biochemistry 40, 1213-1227.

Gomes, E.d.F., Rema, P., Kaushik, S.J., 1995. Replacement of fish meal by plant proteins in the diet of rainbow trout (Oncorhynchus mykiss): digestibility and growth performance. Aquaculture 130, 177-186.

Guillou, A., Soucy, P., Khalil, M., Adambounou, L., 1995. Effects of dietary vegetable and marine lipid on growth, muscle fatty acid composition and organoleptic quality of flesh of brook charr (Salvelinus fontinalis). Aquaculture 136, 351-362.

Heissenberger, M., Watzke, J., Kainz, M., 2010. Effect of nutrition on fatty acid profiles of riverine, lacustrine, and aquaculture-raised salmonids of pre-alpine habitats. Hydrobiologia 650 , 243-254.

Hiratsuka, S., T. Kitagawa, Y. Matsue, M. Hashidume, and S. Wada. 2004. Lipid class and fatty acid composition of phospholipids from the gonads of skipjack tuna. Fisheries Science 70 : 903-909.

Izquierdo, M.S., 1996. Essential fatty acid requirements of cultured marine fish larvae. Aquaculture Nutrition 2, 183-191.

Izquierdo, M.S., Fernandez-Palacios, H., Tacon, A.G.J., 2001. Effect of broodstock nutrition on reproductive performance of fish. Aquaculture 197, 25-42.

Jobling, M., 2003. Do changes in Atlantic salmon, Salmo salar L., fillet fatty acids following a 
dietary switch represent wash-out or dilution? Test of a dilution model and its application. Aquaculture Research 34, 1215-1221.

Jobling, M., 2004. 'Finishing' feeds for carnivorous fish and the fatty acid dilution model. Aquaculture Research 35, 706-709.

Kainz, M., Arts, M.T., Mazumder, A., 2004. Essential fatty acids in the planktonic food web and their ecological role for higher trophic levels. Limnology and Oceanography 49, 1784-1793.

Karalazos, V,, Bendiksen, E.A., Dick, J.R. Tocher, D.R. Bell, J.G. (2011). Influence of the dietary protein:lipid ratio and fish oil substitution on fatty acid composition and metabolism of Atlantic salmon (Salmo salar) reared at high water temperatures. British Journal of Nutrition, 105. 1012-1025.

Kaushik, S.J., Cravedi, J.P., Lalles, J.P., Sumpter, J., Fauconneau, B., Laroche, M., 1995. Partial or total replacement of fish meal by soybean protein on growth, protein utilization, potential estrogenic or antigenic effects, cholesterolemia and flesh quality in rainbow trout, Oncorhynchus mykiss. Aquaculture 133, 257-274.

Krogdahl, Ã., 1989. Alternative protein sources from plants contain antinutrients affecting digestion in salmonids, The current status of fish nutrition in aqua-culture. Proceedings of the third international symposium on feeding and nutrition in fish. August, pp. 253-261.

Kirsch, P.E., Iverson, S.J., Bowen, W.D., Kerr, S.R., Ackman, R.G., 1998. Dietary effects on the fatty acid signature of whole Atlantic cod (Gadus morhua). Canadian Journal of Fisheries and Aquatic Sciences 55, 1378-1386.

Liener, I., 1969. Protease inhibitors. In: Liener, I. (ed.): Toxic constituents of plant foodstuffs. Elsevier, pp 7-68.

Mourente, G., Bell, J.G., 2006. Partial replacement of dietary fish oil with blends of vegetable oils (rapeseed, linseed and palm oils) in diets for European sea bass (Dicentrarchus labrax L.) over a long term growth study: Effects on muscle and liver fatty acid composition and effectiveness of a fish oil finishing diet. Comparative Biochemistry and Physiology Part B: Biochemistry and Molecular Biology 145, 389-399.

Mourente, G., Odriozola, J.M., 1990. Effect of broodstock diets on lipid classes and their fatty acid composition in eggs of gilthead sea bream (Sparus aurata L.). Fish Physiology and Biochemistry 8, 93-101.

Mourente, G., Tocher, D.R., Sargent, J.R., 1991. Specific accumulation of docosahexaenoic acid $(22: 6 n-3)$ in brain lipids during development of juvenile turbot Scophthalmus maximus $\mathrm{L}$. Lipids 26, 871-877.

Murray, D.S., Hager, H., Tocher, D.R. \& Kainz, M. 2014. Effect of partial dietary fish meal and fish oil replacement pumpkin kernel cake and rapeseed oil on fatty acid composition and metabolism in Arctic charr. (Salvelinus alpinus). Aquaculture 431, 85-91.

Nyina-Wamwiza, L., Wathelet, B., Richir, J., Rollin, X., Kestemont, P., 2010. Partial or total replacement of fish meal by local agricultural by-products in diets of juvenile African catfish (Clarias gariepinus): growth performance, feed efficiency and digestibility. Aquaculture Nutrition, 16, 237-247.

Pettersson, A., Pickova, J., Brännäs, E., 2009. Effects of crude rapeseed oil on lipid composition in Arctic charr Salvelinus alpinus. Journal of Fish Biology, 75, 1446-1458.

Pustowka, C., McNiven, M.A., Richardson, G.F., Lall, S.P., 2000. Source of dietary lipid affects sperm plasma membrane integrity and fertility in rainbow trout (Oncorhynchus mykiss) (Walbaum) after cryopreservation. Aquaculture Research 31, 297-305.

Sargent, J., Bell, G., McEvoy, L., Tocher, D.R., Estevez, A., 1999. Recent developments in the essential fatty acid nutrition of fish. Aquaculture 177, 191-199. 
Sargent, J.R., Tocher, D.R., Bell, J.G., 2002. The lipids. In Fish Nutrition (Halver, J.E. and Hardy, R.W, eds.) 3rd Edition, Ch.4, pp. 181-257, Academic Press, San Diego.

Saura-Calixto, F., Canellas, J., Garcia-Raso, J., 1983. Determination of hemicellulose, cellulose and lignin contents of dietary fibre and crude fibre of several seed hulls. Data comparison. Zeitschrift fur Lebensmittel-Untersuchung und Forschung 177, 200-202.

Sheridan, M.A., Allen, W.V., Kerstetter, T.H., 1985. Changes in the fatty acid composition of steelhead trout, Salmo gairdnerii Richardson, associated with parr-smolt transformation. Comparative Biochemistry and Physiology Part B: Comparative Biochemistry 80, 671-676.

Stillwell, W., Wassall, S.R., 2003. Docosahexaenoic acid: membrane properties of a unique fatty acid. Chemistry and physics of lipids 126, 1-27.

Tocher, D.R., Fraser, A.J., Sargent, J.R., Gamble, J.C., 1985. Lipid class composition during embryonic and early larval development in Atlantic herring (Clupea harengus, L.). Lipids 20, 84-89.

Tocher, D.R., Bell, J.G., Dick, J.R., Henderson, R.J., McGhee, F., Michell, D., Morris, P.C., 2000. Polyunsaturated fatty acid metabolism in Atlantic salmon (Salmo salar) undergoing parrsmolt transformation and the effects of dietary linseed and rapeseed oils. Fish Physiology and Biochemistry, 23, 59-73.

Tocher, D.R., Agaba, M., Hastings, N., Bell, J.G., Dick, J.R., Teale, A.J., 2001. Nutritional regulation of hepatocyte fatty acid desaturation and polyunsaturated fatty acid composition in zebrafish (Danio rerio) and tilapia (Oreochromis niloticus). Fish Physiology and Biochemistry. 24, 309-320.

Tocher, D.R., 2003. Metabolism and functions of lipids and fatty acids in teleost fish. Reviews in Fisheries Science 11, 107-184.

Tocher, D.R., Bell, J.G., McGhee, F., Dick, J.R., Fonseca-Madrigal, J., 2003. Effects of dietary lipid level and vegetable oil on fatty acid metabolism in Atlantic salmon (Salmo salar L.) over the whole production cycle. Fish Physiology and Biochemistry 29, 193-209.

Torstensen, B., Lie, O., Froyland, L., 2000. Lipid metabolism and tissue composition in Atlantic salmon (Salmo salar L.)- Effects of capelin oil, palm oil, and oleic acid-enriched sunflower oil as dietary lipid sources. Lipids 35, 653-664.

Turchini, G.M., Francis, D.S., 2009. Fatty acid metabolism (desaturation, elongation and $\beta-$ oxidation) in rainbow trout fed fish oil-or linseed oil-based diets. British Journal of Nutrition $102,69-81$

Turchini, G.M., Torstensen, B.E., Ng, W.-K., 2009. Fish oil replacement in finfish nutrition. Reviews in Aquaculture 1, 10-57.

Wassall, S.R., Brzustowicz, M.R., Shaikh, S.R., Cherezov, V., Caffrey, M., Stillwell, W., 2004. Order from disorder, corralling cholesterol with chaotic lipids: the role of polyunsaturated lipids in membrane raft formation. Chemistry and Physics of Lipids 132, 79-88.

Wiegand, M.D., 1996. Composition, accumulation and utilization of yolk lipids in teleost fish. Reviews in Fish Biology and Fisheries 6, 259-286.

\section{Figure caption}


Figure 1. Dorsal muscle DHA (mean $\pm \mathrm{SD}$ ) contents (mg/g total lipids) of Arctic charr fed diets containing different DHA contents. Significant differences are indicated above relevant months.

Figure 2. Ventral muscle DHA (mean $\pm \mathrm{SD}$ ) contents (mg/g total lipids) of Arctic charr fed diets containing different DHA contents. Significant differences are indicated above relevant months.

Figure 3. DHA per unit biomass accrual in dorsal muscle tissue ( $\mu \mathrm{g} \mathrm{DHA} / \mathrm{g} / \mathrm{day})$.

Figure 4. DHA per unit biomass accrual in ventral muscle tissue ( $\mu \mathrm{g} \mathrm{DHA} / \mathrm{g} / \mathrm{day})$.

Figure 5. DHA retention ratios in dorsal muscle of Arctic charr during the feeding period.

Figure 6. DHA retention ratios in ventral muscle of Arctic charr during the feeding period.

Figure 7. Relationships between DHA retention ratios in dorsal muscle and fish weight, grouped by dietary treatment with corresponding $\mathrm{P}$-value from regression analysis.

Figure 8. Relationship between DHA retention ratios in ventral muscle and fish weight, grouped by dietary treatment with corresponding $\mathrm{P}$-value from regression analysis. 


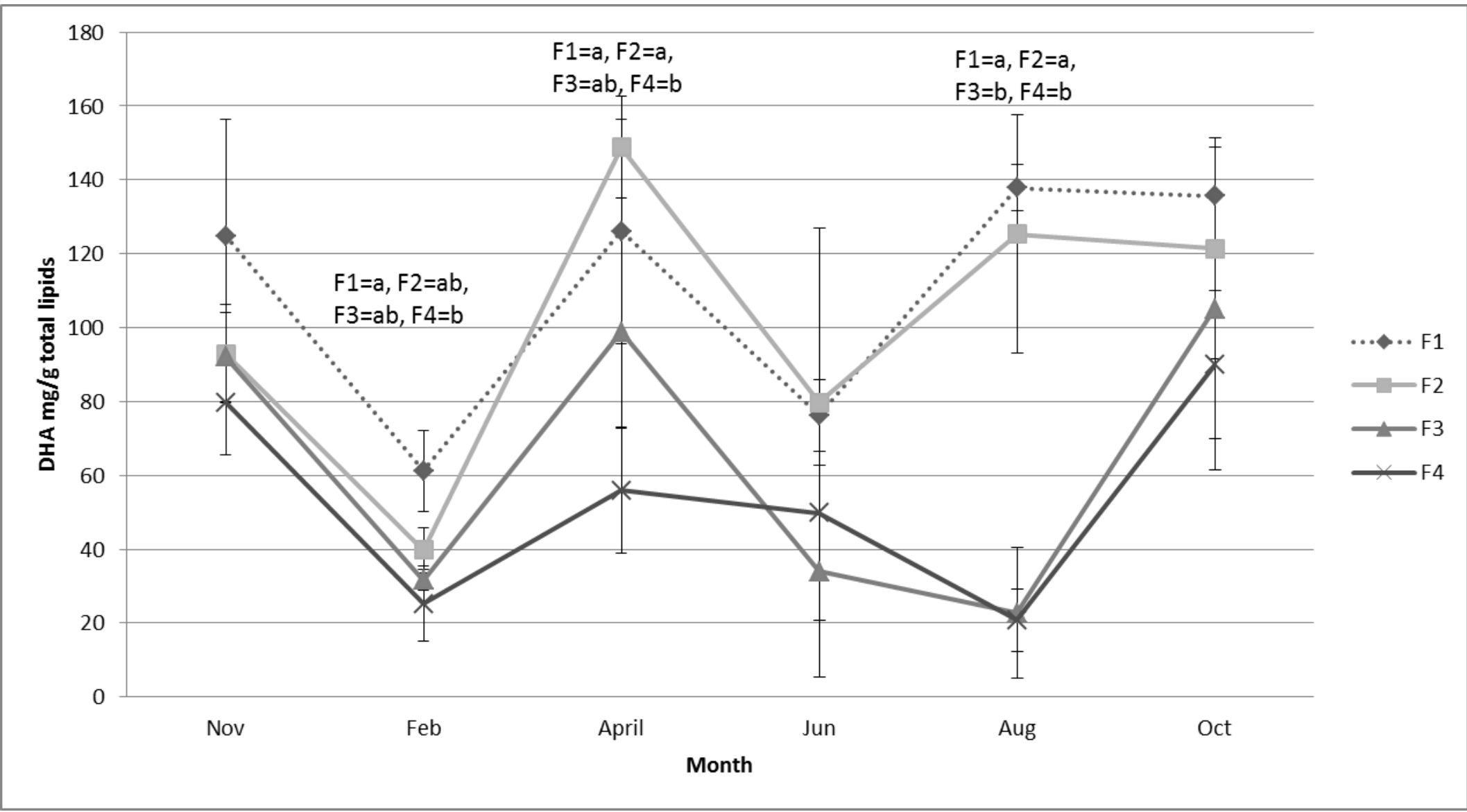

Figure 1. 


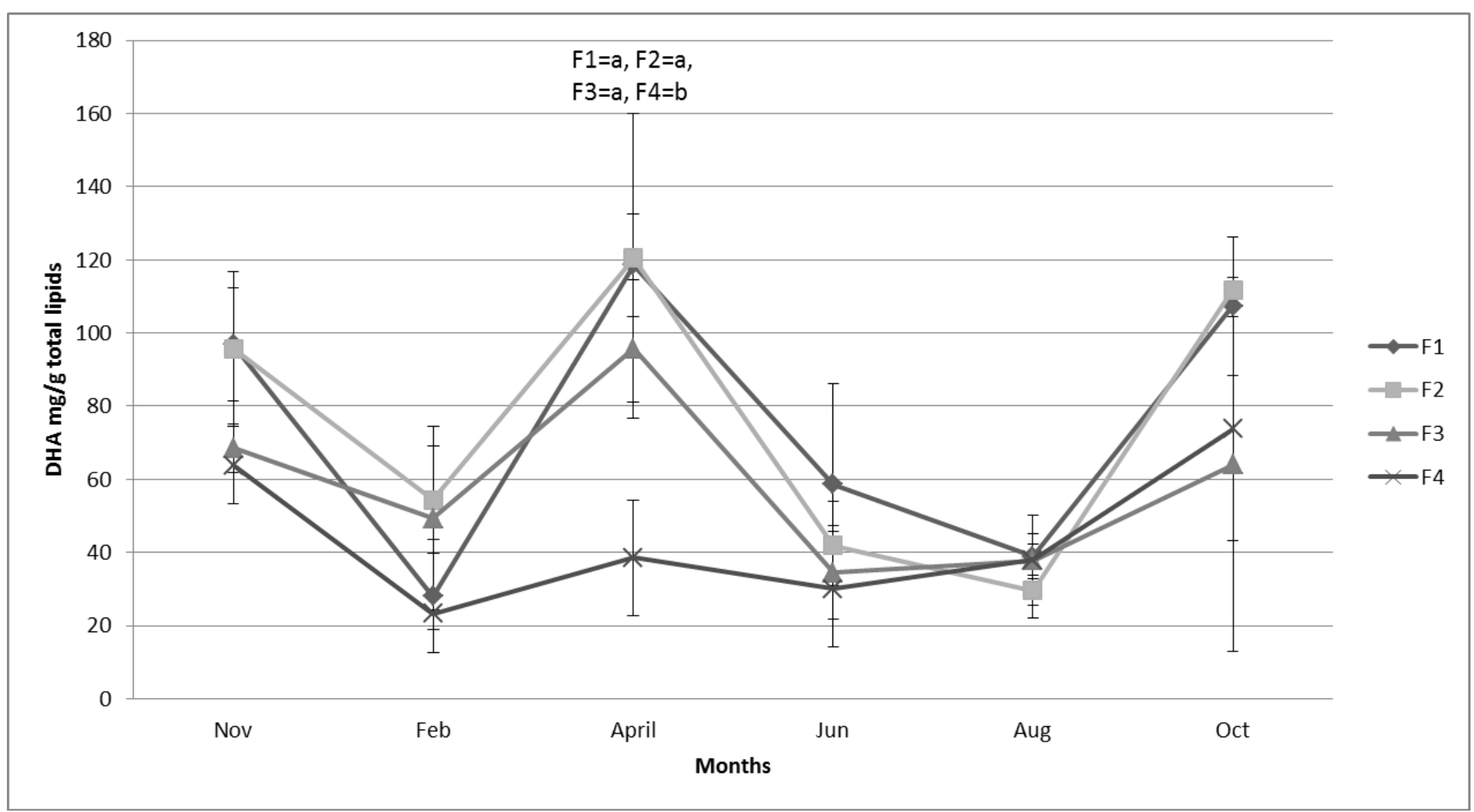

$\begin{array}{ll}6 & \\ & \text { Figure } 2 .\end{array}$ 


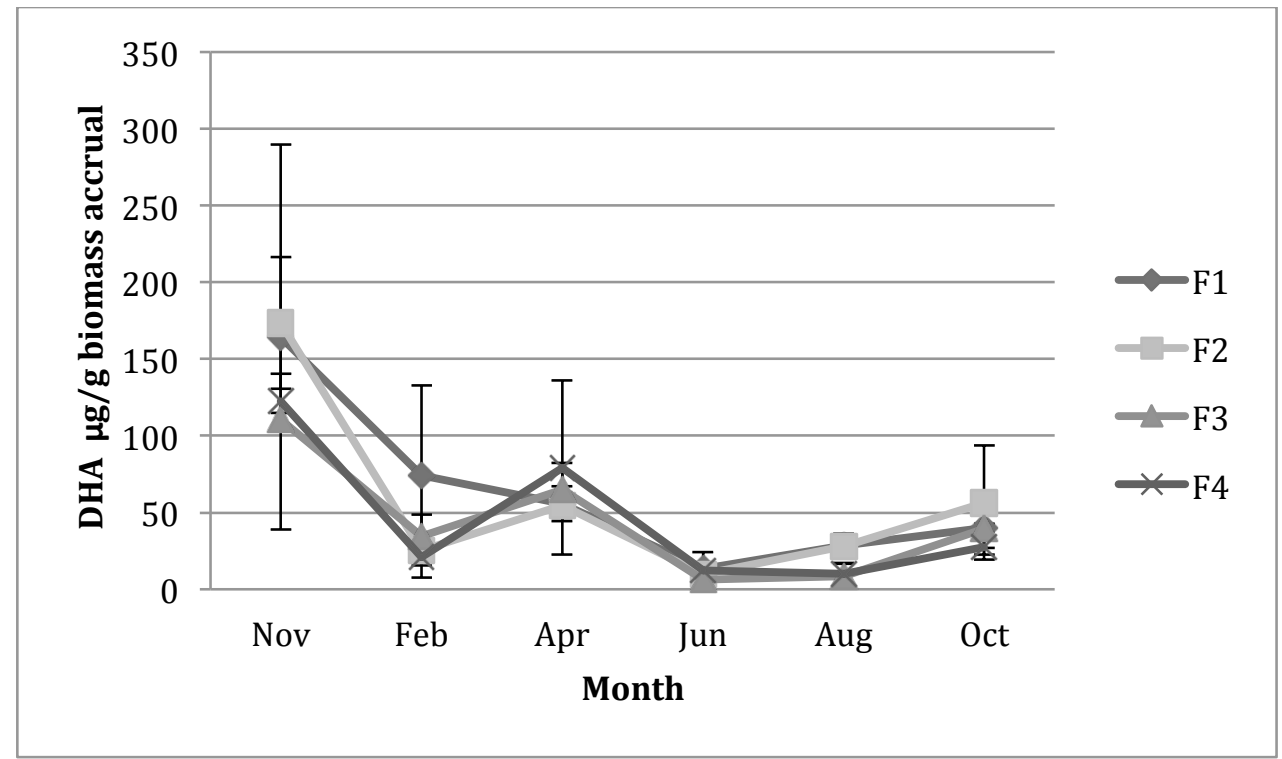

\section{Figure 3.}

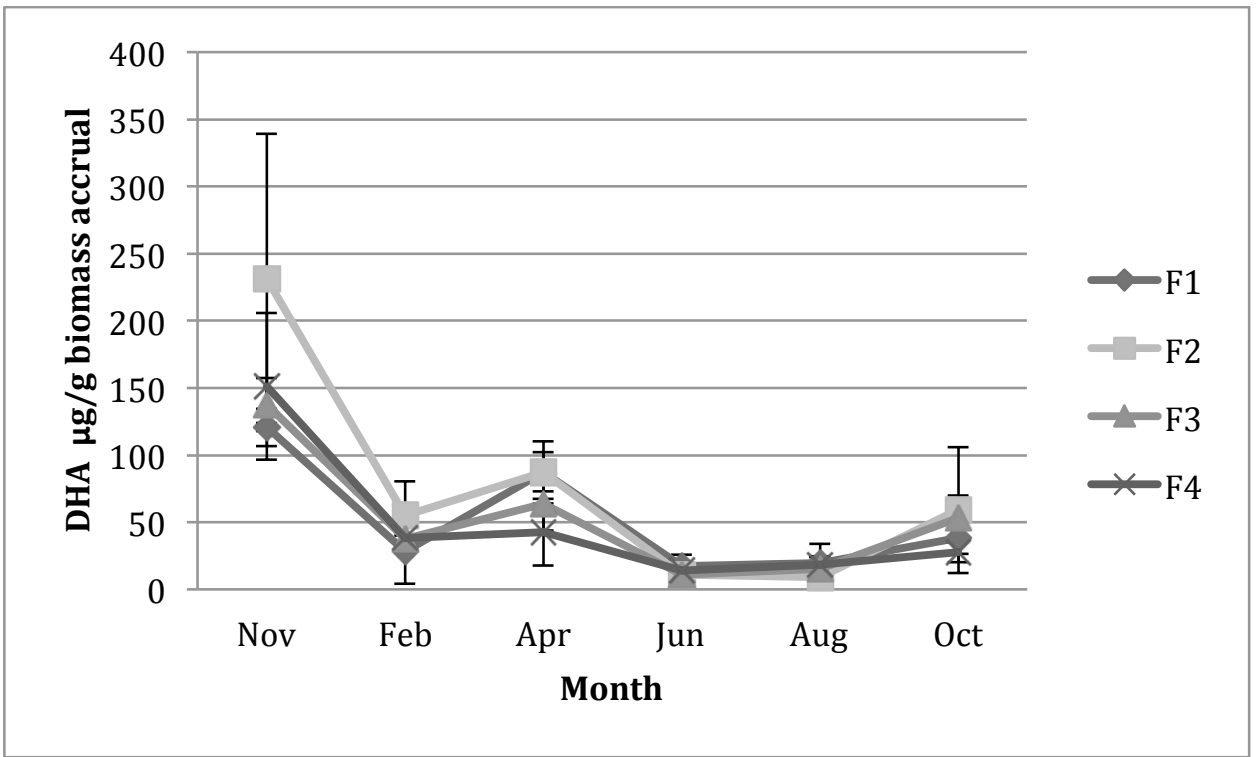

Figure 4. 


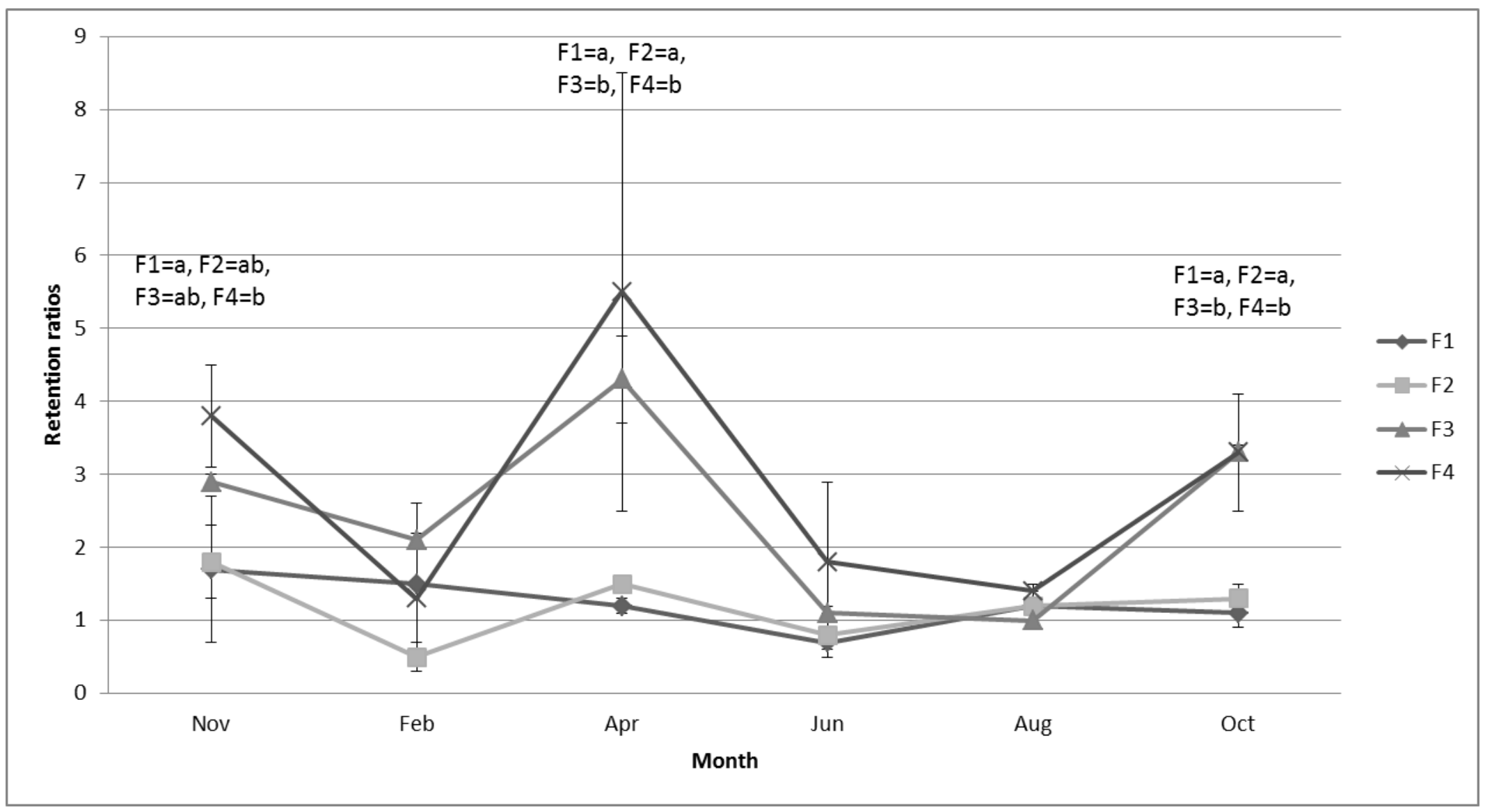

Figure 5. 


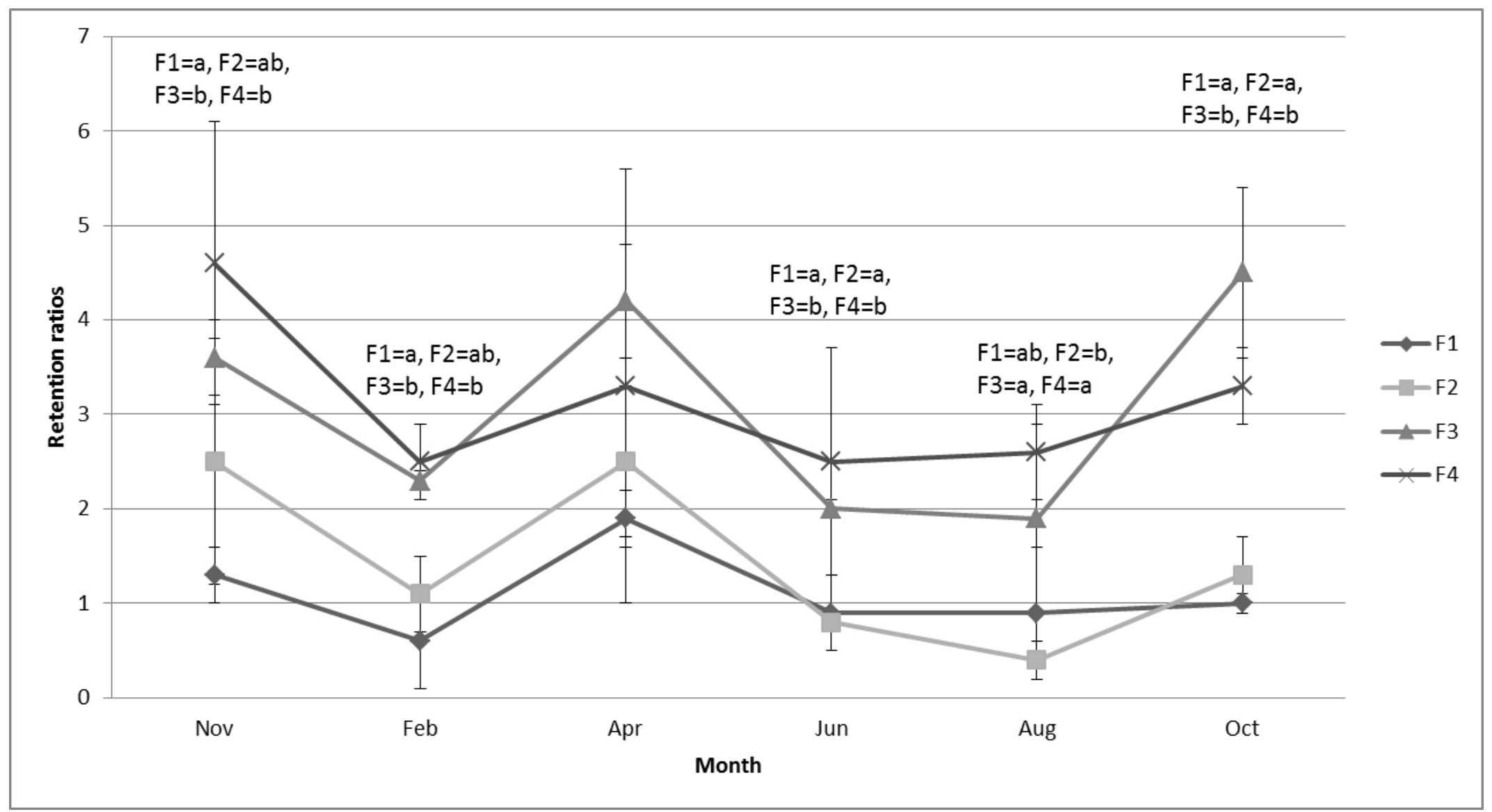

Figure 6. 


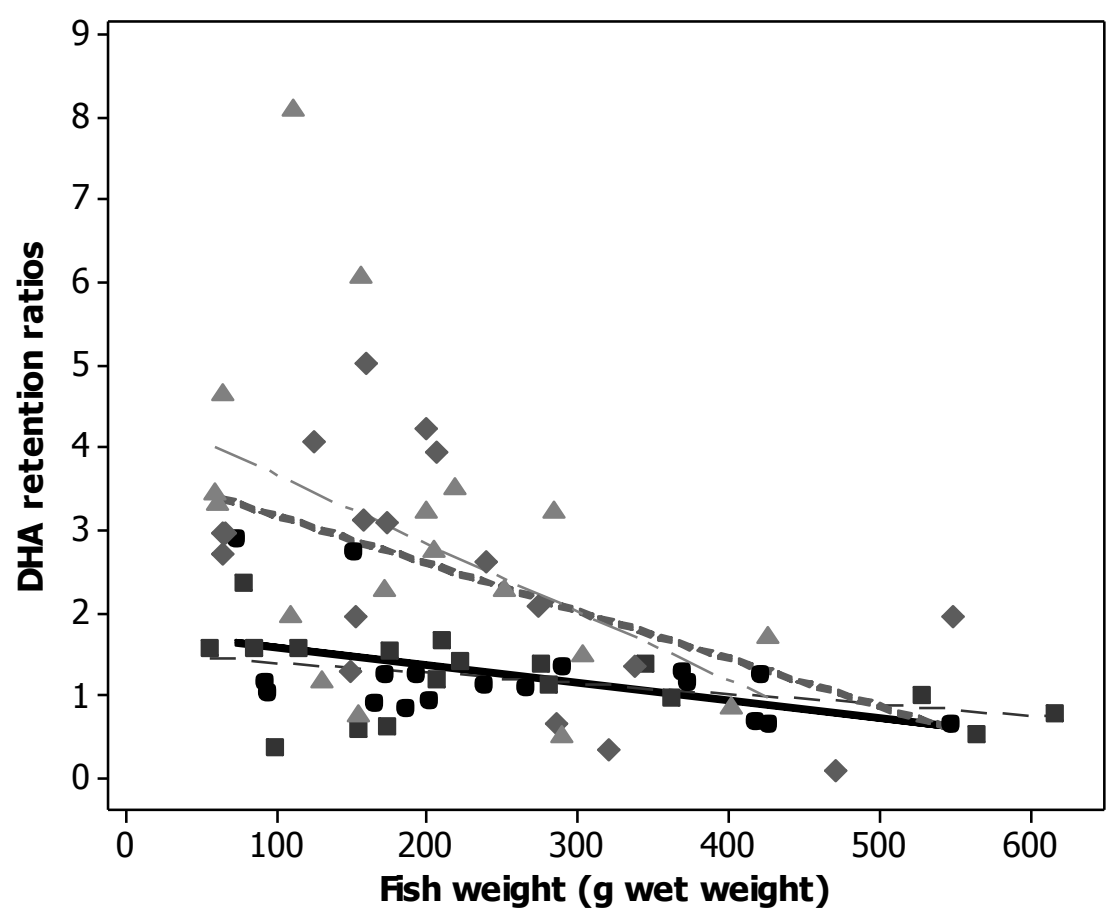

Figure 7.

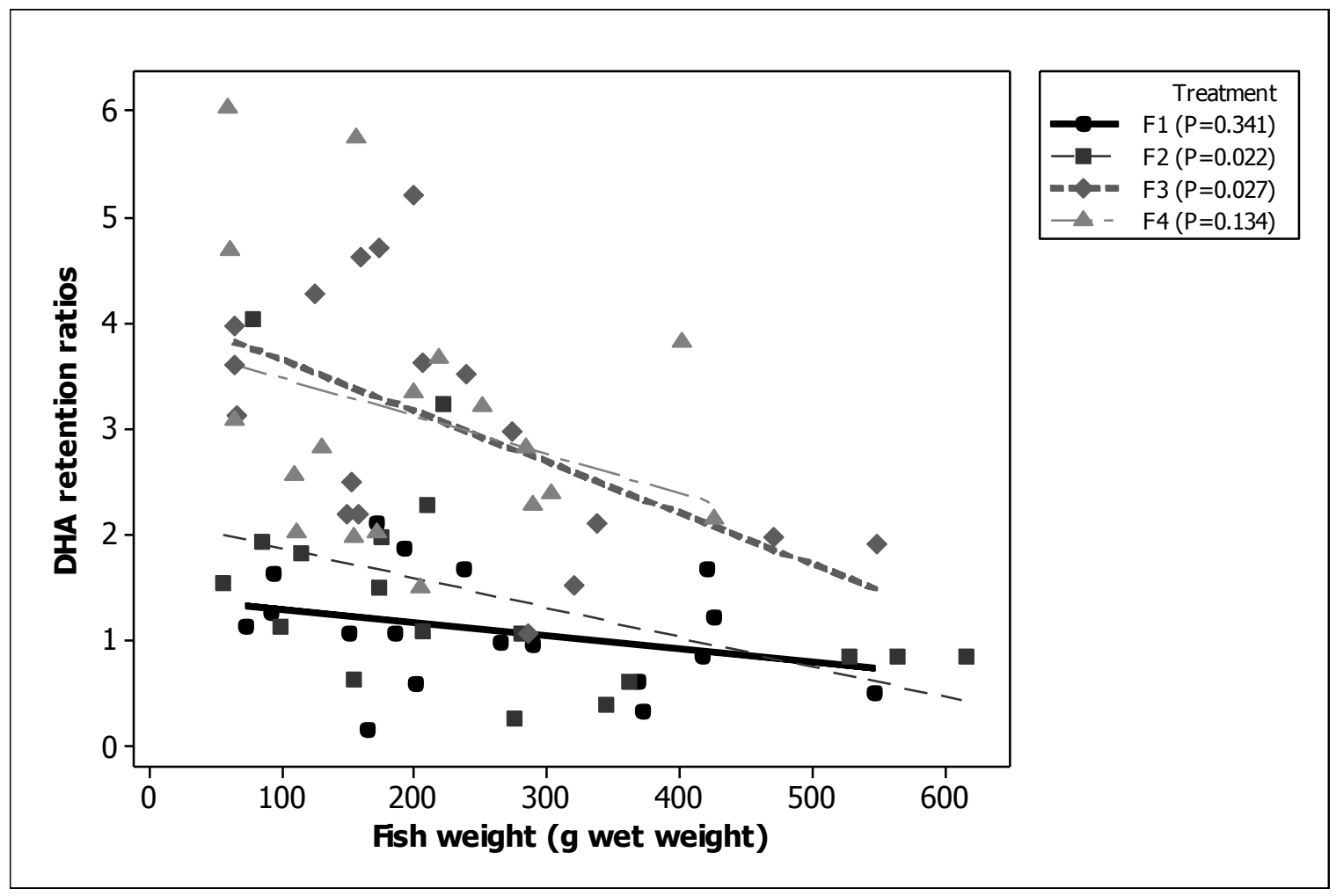

$5 \quad$ Figure 8.

6

7

8 


\begin{tabular}{l|llll}
\hline Ingrediants & $F 1$ & F2 & F3 & F4 \\
\hline Fish meal, anchovy, super prime, 67\% CP & 35.0 & 22.5 & 22.5 & 10.0 \\
Pumpkin kernel cake, 59\% CP, 11\% C. Lipids & - & 12.5 & 12.5 & 25.0 \\
Sunflower protein concentrate, 46\% CP & 16.8 & 13.8 & 13.8 & 11.0 \\
Haemoglobin powder & 7.5 & 7.5 & 7.5 & 7.5 \\
Rapeseed cake, 32.5\% CP, 9\% CL & 5.0 & 5.0 & 5.0 & 5.0 \\
Wheat gluten 80\% CP & - & 3.34 & 3.34 & 6.27 \\
Wheat, feed quality & 10.5 & 9.7 & 9.7 & 8.5 \\
Wheat feed flour & 6.0 & 6.0 & 6.0 & 6.0 \\
Fish oil (Salmon oil) & 18.1 & 17.8 & 3.0 & 3.0 \\
Rapeseed oil & - & - & 14.8 & 14.5 \\
Monocalciumphosphate & - & 0.6 & 0.6 & 1.45 \\
Lysine-HCL & - & 0.16 & 0.16 & 0.68 \\
Premix & 0.8 & 0.8 & 0.8 & 0.8 \\
Diamol (marker) & 0.3 & 0.3 & 0.3 & 0.3 \\
\hline
\end{tabular}

Table 2. Polyunsaturated fatty acid (PUFA) contents (mean \pm SD; $g$ FA / kg dry weight of diet) of experimental feeds.

16

\begin{tabular}{l|cccc}
\hline Fatty Acids & $F 1$ & $F 2$ & $F 3$ & $F 4$ \\
\hline & & & & \\
$18: 3(n-3)$ & $7.4 \pm 1.4$ & $7.3 \pm 2.7$ & $12.0 \pm 1.9$ & $12.0 \pm 2.1$ \\
$18: 4(n-3)$ & $0.0 \pm 0.0$ & $0.0 \pm 0.0$ & $0.0 \pm 0.0$ & $0.0 \pm 0.0$ \\
$20: 3(n-3)$ & $0.5 \pm 0.0$ & $0.5 \pm 0.0$ & $0.1 \pm 0.0$ & $0.1 \pm 0.0$ \\
$20: 4(n-3)$ & $0.0 \pm 0.0$ & $0.0 \pm 0.0$ & $0.0 \pm 0.0$ & $0.0 \pm 0.0$ \\
$20: 5(n-3)$ & $8.5 \pm 1.8$ & $7.0 \pm 1.9$ & $2.8 \pm 0.2$ & $2.1 \pm 0.7$ \\
$22: 5(n-3)$ & $1.7 \pm 0.4$ & $1.6 \pm 0.4$ & $0.5 \pm 0.0$ & $0.5 \pm 0.1$ \\
$22: 6(n-3)$ & $8.4 \pm 1.5$ & $7.0 \pm 2.7$ & $2.5 \pm 0.8$ & $2.0 \pm 0.7$ \\
Total n-3 PUFA & $26.5 \pm 5.1$ & $23.4 \pm 7.7$ & $17.8 \pm 2.9$ & $16.7 \pm 3.7$ \\
& & & & \\
$18: 2(n-6)$ & $23.8 \pm 11.0$ & $25.1 \pm 2.9$ & $36.4 \pm 1.0$ & $38.9 \pm 3.2$ \\
$18: 3(n-6)$ & $0.2 \pm 0.1$ & $0.2 \pm 0.0$ & $0.0 \pm 0.0$ & $0.0 \pm 0.0$ \\
$20: 2(n-6)$ & $3.1 \pm 1.2$ & $2.4 \pm 0.7$ & $1.0 \pm 0.0$ & $1.1 \pm 0.4$ \\
$20: 3(n-6)$ & $0.3 \pm 0.1$ & $0.3 \pm 0.0$ & $0.1 \pm 0.0$ & $0.1 \pm 0.1$ \\
$20: 4(n-6)$ & $0.7 \pm 0.1$ & $0.5 \pm 0.2$ & $0.2 \pm 0.0$ & $0.2 \pm 0.0$ \\
$22: 4(n-6)$ & $0.1 \pm 0.0$ & $0.1 \pm 0.0$ & $0.0 \pm 0.0$ & $0.0 \pm 0.0$ \\
Total n-6 PUFA & $30.0 \pm 12.9$ & $30.4 \pm 4.2$ & $38.5 \pm 1.1$ & $41.0 \pm 4.1$ \\
\hline
\end{tabular}


19 Table 3. Proximate composition of experimental diets ( $\mathrm{g} / 100 \mathrm{~g}$ of diet).

20

\begin{tabular}{l|cccc}
\hline & $F 1$ & $F 2$ & $F 3$ & $F 4$ \\
\hline & & & & \\
Protein & $43.2 \pm 1.0$ & $43.7 \pm 2.4$ & $44.6 \pm 2.1$ & $44.0 \pm 4.0$ \\
Lipid & $25.1 \pm 2.3$ & $24.5 \pm 1.4$ & $24.4 \pm 1.1$ & $23.8 \pm 3.4$ \\
Ash & $10.2 \pm 1.3$ & $8.4 \pm 0.0$ & $8.0 \pm 0.1$ & $8.5 \pm 0.9$ \\
Moisture & $7.2 \pm 0.3$ & $5.8 \pm 0.3$ & $8.1 \pm 0.3$ & $8.8 \pm 1.3$ \\
\hline
\end{tabular}

21

22 Table 4. Growth and feed utilisation (mean \pm SD) of Arctic charr fed different diets over the 401 day 23 experimental period.

24

\begin{tabular}{l|cccc}
\hline & $F 1$ & $F 2$ & $F 3$ & $F 4$ \\
\hline & & & & \\
Initial weight $\left(g\right.$ fish $\left.^{-1}\right)$ & $11.1 \pm 0.3$ & $10.3 \pm 0.5$ & $10.4 \pm 0.7$ & $10.3 \pm 0.9$ \\
Final weight $\left(g\right.$ fish $\left.^{-1}\right)$ & $350.0 \pm 22.8^{\mathrm{a}}$ & $291.9 \pm 1.4^{\mathrm{b}}$ & $270.3 \pm 8.0^{\mathrm{bc}}$ & $236.3 \pm 16.9^{\mathrm{c}}$ \\
Weight gain $\left(\mathrm{g}\right.$ fish $\left.^{-1}\right)$ & $338.8 \pm 22.5^{\mathrm{a}}$ & $281.6 \pm 12.2^{\mathrm{b}}$ & $259.9 \pm 8.4^{\mathrm{bc}}$ & $226.0 \pm 17.1^{\mathrm{c}}$ \\
Total feed deposited in & $20.1 \pm 1.1^{\mathrm{a}}$ & $16.9 \pm 0.6^{\mathrm{b}}$ & $14.7 \pm 1.5^{\mathrm{b}}$ & $16.0 \pm 1.1^{\mathrm{b}}$ \\
tanks $(\mathrm{kg} /$ tank $)$ & & & & \\
Feed conversion ratio & $0.91 \pm 0.05^{\mathrm{a}}$ & $1.02 \pm 0.05^{\mathrm{b}}$ & $1.06 \pm 0.09^{\mathrm{b}}$ & $1.13 \pm 0.11^{\mathrm{c}}$ \\
\hline
\end{tabular}

